\title{
PERSEPSI MAHASISWA NERS UNIVERSITAS HARAPAN BANGSA TENTANG PEMBIMBING KLINIK
}

\author{
Tri Sumarni1, RosiKurniaSugiharti² \\ 1 Prodi Keperawatan D3, Universitas Harapan Bangsa Purwokerto \\ 2Prodi Kebidanan D3, Universitas Harapan Bangsa Purwokerto \\ Jalan Raden Patah No. 100 Purwokerto, Jawa Tengah \\ Email: trisumarni@uhb.ac.id
}

\begin{abstract}
ABSTRAK
Latar Belakang: Pembelajaran klinik disepakati menjadi bagian penting dari pendidikan keperawatan. Pembimbing klinik yang kompeten akan memfasilitasi mahasiswa dalam belajar. Agar efektif melakukan peran tersebut, kompetensi profesional, hubungan interpersonal, karakter pribadi dan kemampuan mengajar dibutuhkan oleh pembimbing klinik.Tujuan: Penelitian ini bertujuan untuk mengetahui persepsi mahasiswa ners tentang pembimbing klinik. Metode: Jenis penelitian ini adalah observasi kuantitatif dengan desain cross sectional dengan menggunakan sampel sebanyak 81 mahasiswa ners.Pengambilan sampel dengan total sampling. Teknik pengumpulan data dengan menggunakan kuesioner. Instrumen penelitian menggunakan kuesioner Nursing Clinical Teacher Effectiveness Inventory (NCTEI). Analisis data menggunakan uji statistikt test karena data terdistribusi normal ( $p>$ 0,2 ). Hasil: Pembimbing klinik yang efektif menurut persepsi mahasiswa yaitu yang mempunyai kompetensi profesional (mean 4,01), sementara yang tidak efektif terkait hubungan interpersonal (mean 2,78). Perbedaan terbesar antara pembimbing klinik yang efektif dan tidak efektif menurut persepsi mahasiswa yaitu di kemampuan mengajar (nilai t 17,88) dan kompetensi profesional (nilai t 17,74). Hasil penelitian menunjukkan bahwa pembimbing klinik yang efektif jika mempunyai kemampuan mengajar dan mempunyai kompetensi profesional, sehingga harapannya pembimbing klinik akan meningkatkan kemampuan mengajar dan kompetensi profesional untuk membantu mahasiswa mencapai tujuan pembelajaran klinik.
\end{abstract}

Kata Kunci: persepsi; pembimbing klinik yang efektif; pembimbing klinik yang tidak efektif

\begin{abstract}
Background: Clinical learning is agreed to be an important part of nursing education. Competent clinical instructor will facilitate students in learning. In order to be effective in carrying out this role, professional competence, interpersonal relations, personal character and teaching skills are needed by the clinical instructor. Objective: This study aims to determine the perceptions of students about clinical instructor. Method: This type of research is quantitative observation with a cross sectional design using a sample of 81 student nurses. Sampling with total sampling. Data collection techniques using a questionnaire. The research instrument used the Nursing Clinical Teacher Effectiveness Inventory (NCTEI) questionnaire. Data analysis using statistical test $t$ test because the data is normally distributed ( $p>$ 0.2). Results: Clinical instructor were effective according to students' perceptions of having professional competence (mean 4.01), while those that were ineffective were related to interpersonal relations (mean 2.78). The biggest difference between effective and ineffective clinical instructor according to student perceptions is in teaching ability (t value 17.88) and professional competence (t value 17.74). Conclusions \& Suggestions: The results of the study show that clinical instructor are effective if they have the ability to teach and have professional competence, so that the hope that clinical instructor will improve teaching skills and professional competencies to help students achieve clinical learning goals.
\end{abstract}

Keywords: perception; effective clinical instructor; ineffective clinical instructor 


\section{LATAR BELAKANG}

Proses mendidik mahasiswa keperawatan, diperlukan pembelajaran teori di kelas dan penerapan teori di lapangan (klinik) (Toelke, 2012), sehingga pembelajaran klinik disepakati menjadi bagian penting dari pendidikan keperawatan (Dunn \& Hansford, 2010). Dalam pembelajaran klinik, mahasiswa dapat berlatih keterampilan, menerapkan teori ke dalam praktik, serta berlatih mengambil ke putusan (Papp, Markkanen\& Von Bonsdorff, 2009).

Meskipun pembelajaran klinik sangat bermanfaat, pengalaman klinis mahasiswa keperawatan bervariasi, bias positif maupun negatif (Killam \&Heerschap, 2012). Pengalaman variatif tersebut dipengaruhi oleh pembimbing klinik, support dari staf perawat, rasio pembimbing klinik dan mahasiswa, kualitas pengarahan pra klinik (Lawalet all, 2016).

Motivasi dan ketertarikan yang rendah pada mahasiswa keperawatan, akan berdampak pada proses pembelajaran klinik, sehingga pembimbing klinik diharapkan mengembangkan strategi yang efektif untuk meningkatkan pengetahuan dan keterampilan mahasiswa (Tang et al., 2010). Pembimbing klinik berperan dalam memberikan contohcontoh teori yang diaplikasikan di lahan klinik. Dalam hal ini, pembimbing klinik merupakan orang yang paling penting dalam mempengaruhi mahasiswa dalam pembelajaran klinik. Pembimbing klinik diharapkan meningkatkan berpikir kritis mahasiswa, melatih pengambilan keputusan, meningkatkan pengetahuan, sikap dan keterampilan klinik (Heshmatiet all, 2010).Gillespie (2010) juga menyatakan bahwa support dari pembimbing klinik akan meningkatkan kepercayaan diri mahasiswa, motivasi untuk belajar dan motivasi untuk berkembang.

Pembimbing klinik keperawatan bertanggung jawab untuk memastikan bahwa mahasiswa belajar bagaimana menerapkan teori, membimbing mahasiswa untuk mendapatkan pengalaman, melatih skill dan membimbing menjadi individu yang dewasa (Clayton, Lypek, \& Connelly, 2010). Di saat yang sama, pembimbing klinik juga bertanggung jawab untuk memastikan pasien menerima pelayanan keperawatan yang berkualitas tinggi, mendapatkan pelayanan yang aman yang didapat dari mahasiswa ketika praktik (DeLong \& Bechtel, 2009). Agar efektif melakukan peran tersebut, kompetensi profesional, hubungan interpersonal, karakter pribadi dan kemampuan mengajar dibutuhkan oleh pembimbing klinik.

Berbagai penelitian sudah dilakukan untuk mengetahui kompeten siapa yang harus dimiliki pembimbing klinik. Penelitian sebelumnya menyatakan atribut penting dari pembimbing klinik adalah kompetensi profesional (Johnsen \&Aasgaard, 2009), sementara penelitian lain menyatakan hubungan interpersonal merupakanatribut yang penting (Bergman \&Gaitskill, 2010).

Berdasarkan hasil survey, mahasiswa mengeluh masih banyak pembimbing klinik di rumah sakit yang belum semuanya memberikan support kemahasiswa. Perawat selain dibebani dengan tugas sebagai pemberi pelayanan keperawatan kepada pasien dan membimbing mahasiswa juga masih dibebani dengan tugastugas yang sifatnya administrasi.Tujuan dari penelitian ini yaitu untuk mengetahui persepsi mahasiswa ners tentang pembimbing klinik.

\section{METODE}

Jenis penelitian ini adala hpenelitian observatif yang bersifat kuantitatif dengan rancangan penelitian cross sectional, dimana pengukuran dan pengamatannya dilakukan secara simultan pada satu saat (sekali waktu) (Swarjana, 2014). Populasi dalam penelitian ini adalah seluruh mahasiswa ners regular Universitas Harapan Bangsa angkatan tahun akademik 2017/2018 yang berjumlah 81 mahasiswaners. Teknik pengambilan sampel dalam penelitian ini dengan total sampling. Sampel dalam penelitian ini berjumlah 81 mahasiswa. Penelitian ini mengukur variable persepsi mahasiswa ners tentang pembimbing klinik yang efektif dan tidak efektif. Kuesioner menggunakan Nursing Clinical Teacher Effectiveness Inventory (NCTEI). Analisis data menggunakan uji statistik $\mathrm{t}$ dependen (data terdistribusi normal $(p>0,2)$. 
HASIL

Tabel 1

Persepsi Mahasiswa Ners tentang Pembimbing Klinik yang Efektif dan Tidak Efektif

\begin{tabular}{|c|c|c|c|c|}
\hline NO & Item & $\begin{array}{c}\text { Efektif } \\
\text { Mean (SD) }\end{array}$ & $\begin{array}{l}\text { Tidak efektif } \\
\text { Mean (SD) }\end{array}$ & t value \\
\hline \multicolumn{2}{|r|}{ Kompetensi Profesional } & 4,01 & 2,71 & 17,74 \\
\hline 1 & Tertarik terhadap perawatan pasien & $4,02(0,75)$ & $2,68(0,84)$ & 11,27 \\
\hline 2 & Menerapkan teori di praktik klinik & $3,99(0,78)$ & $2,72(0,86)$ & 11,89 \\
\hline 3 & Menjadi role model untuk mahasiswa & $3,85(0,86)$ & $2,59(0,81)$ & 10,59 \\
\hline 4 & $\begin{array}{l}\text { Terampil ketika melakukan tindakan } \\
\text { keperawatan }\end{array}$ & $4,16(0,69)$ & $2,83(0,80)$ & 13,21 \\
\hline 5 & Mempunyai pengetahuan yang cukup banyak & $4,35(0,63)$ & $3,02(0,81)$ & 11,49 \\
\hline 6 & $\begin{array}{l}\text { Menerangkan dan mencontohkan teknik } \\
\text { tindakan yang terbaru }\end{array}$ & $3,70(0,87)$ & $2,41(0,73)$ & 11,60 \\
\hline \multicolumn{2}{|r|}{ Hubungan interpersonal } & 3,78 & 2,78 & 12,88 \\
\hline 7 & $\begin{array}{l}\text { Menghindari supervisi yang berlebihan ke } \\
\text { tugas-tugas mahasiswa }\end{array}$ & $2,77(1,02)$ & $2,81(0,91)$ &,- 31 \\
\hline 8 & $\begin{array}{l}\text { Memberikan feed back (umpan balik) atas } \\
\text { capaian mahasiswa }\end{array}$ & $3,89(0,77)$ & $2,68(0,83)$ & 11,21 \\
\hline 9 & $\begin{array}{l}\text { Menyelesaikan masalah bersama dengan } \\
\text { mahasiswa }\end{array}$ & $3,70(0,84)$ & $2,42(0,78)$ & 12,67 \\
\hline 10 & $\begin{array}{l}\text { Memperlakukan mahasiswa sebagai manusia } \\
\text { dengan bijaksana }\end{array}$ & $4,01(0,94)$ & $2,70(0,91)$ & 9,72 \\
\hline 11 & Memberikan kritik yang membangun & $4,01(0,84)$ & $2,72(0,95)$ & 11,06 \\
\hline 12 & $\begin{array}{l}\text { Menghindari perilaku otoriter dan mendominasi } \\
\text { mahasiswa }\end{array}$ & $3,58(0,87)$ & $2,64(0,85)$ & 7,05 \\
\hline 13 & $\begin{array}{l}\text { Tidak mengecam mahasiswa didepan orang } \\
\text { lain }\end{array}$ & $3,68(1,34)$ & $3,02(1,01)$ & 4,38 \\
\hline 14 & $\begin{array}{l}\text { Memberikan kesempatan ke mahasiswa untuk } \\
\text { menerangkan }\end{array}$ & $4,01(0,84)$ & $2,77(0,91)$ & 10,75 \\
\hline 15 & $\begin{array}{l}\text { Mempunyai hubungan yang baik dengan } \\
\text { tenaga kesehatan yang lain }\end{array}$ & $4,43(0,63)$ & $3,31(2,39)$ & 4,02 \\
\hline \multicolumn{2}{|r|}{ Karakter pribadi } & 3,99 & 2,63 & 16,14 \\
\hline 16 & $\begin{array}{l}\text { Mampu mengontrol emosi, sabar dan perilaku } \\
\text { kooperatif }\end{array}$ & $4,25(0,71)$ & $2,79(0,83)$ & 13,27 \\
\hline 17 & $\begin{array}{l}\text { Memperlakukan mahasiswa dengan tulus dan } \\
\text { obyektif }\end{array}$ & $4,12(0,74)$ & $2,62(0,71)$ & 14,67 \\
\hline 18 & $\begin{array}{l}\text { Memiliki perilaku antusias ketika sedang } \\
\text { mengajar }\end{array}$ & $4,04(0,64)$ & $2,65(0,80)$ & 14,23 \\
\hline 19 & $\begin{array}{l}\text { Mengelola masalah yang diciptakan oleh } \\
\text { mahasiswa secara wajar }\end{array}$ & $3,91(0,63)$ & $2,69(0,81)$ & 12,49 \\
\hline 20 & $\begin{array}{l}\text { Memaklumi kesalahan mahasiswa dan } \\
\text { menghindari mengomel }\end{array}$ & $3,73(0,89)$ & $2,35(0,95)$ & 9,01 \\
\hline 21 & Empati terhadap mahasiswa & $3,88(0,89)$ & $2,48(0,92)$ & 10,27 \\
\hline 22 & Menerima pendapat yang rasional & $4,04(0,74)$ & $2,75(0,84)$ & 10,86 \\
\hline 23 & Menghormati hak-hak mahasiswa & $4,07(0,84)$ & $2,68(0,92)$ & 10,94 \\
\hline 24 & $\begin{array}{l}\text { Menerima bahwa masing-masing mahasiswa } \\
\text { itu berbeda }\end{array}$ & $4,01(0,81)$ & $2,52(0,95)$ & 10,61 \\
\hline
\end{tabular}


Sumarni, et al,. Persepsi Mahasiswa Ners Universitas Harapan Bangsa Tentang Pembimbing Klinik.

SJKP, Vol. 6, No. 1, Juni 2019, 25-30

\begin{tabular}{|c|c|c|c|c|}
\hline 25 & $\begin{array}{l}\text { Menghindari menjudge mahasiswa secara } \\
\text { subjektif }\end{array}$ & $3,89(0,82)$ & $2,78(0,94)$ & 7,84 \\
\hline \multicolumn{2}{|r|}{ Kemampuan mengajar } & 3,96 & 2,75 & 17,88 \\
\hline 26 & Menjelaskan materi dengan jelas ke mahasiswa & $4,12(0,62)$ & $2,63(0,84)$ & 13,42 \\
\hline 27 & $\begin{array}{l}\text { Memberikan pengetahuan yang relevan ke } \\
\text { mahasiswa }\end{array}$ & $4,11(0,57)$ & $2,72(0,86)$ & 13,11 \\
\hline 28 & $\begin{array}{l}\text { Tidak mengganggu atau mengambil alih ketika } \\
\text { mahasiswa sedang mencoba teknik } \\
\text { keterampilan yang baru }\end{array}$ & $3,63(1,03)$ & $2,89(0,74)$ & 5,54 \\
\hline 29 & Mempunyai harapan yang realistis & $3,95(0,83)$ & $2,88(0,92)$ & 8,93 \\
\hline 30 & Memotivasi mahasiswa untuk belajar & $4,15(0,93)$ & $2,81(1,01)$ & 12,00 \\
\hline 31 & $\begin{array}{l}\text { Mengizinkan mahasiswa untuk bebas } \\
\text { berpendapat dan mengungkapkan } \\
\text { perasaannya }\end{array}$ & $4,06(0,79)$ & $2,79(0,84)$ & 11,58 \\
\hline 32 & $\begin{array}{l}\text { Menggunakan sumber daya RS untuk } \\
\text { mendapatkan banyak pengalaman }\end{array}$ & $4,09(0,72)$ & $3,01(0,87)$ & 9,52 \\
\hline 33 & $\begin{array}{l}\text { Memberikan stimulus atau pertanyaan untuk } \\
\text { meningkatkan kemampuan berpikir mahasiswa }\end{array}$ & $3,94(0,71)$ & $2,77(0,88)$ & 11,48 \\
\hline 34 & $\begin{array}{l}\text { Mendorong mahasiswa untuk belajar dan } \\
\text { berpikir secara mandiri }\end{array}$ & $4,15(0,67)$ & $2,98(0,96)$ & 11,15 \\
\hline 35 & $\begin{array}{l}\text { Mencoba memahami bahwa masing-masing } \\
\text { mahasiswa mempunyai pengalaman belajar } \\
\text { yang berbeda }\end{array}$ & $3,93(0,78)$ & $2,64(0,82)$ & 10,74 \\
\hline 36 & $\begin{array}{l}\text { Menggunakan waktu dengan bijak, sistematis } \\
\text { dan efektif }\end{array}$ & $3,99(0,75)$ & $2,72(0,84)$ & 12,23 \\
\hline 37 & $\begin{array}{l}\text { Menggunakan metode pembelajaran yang } \\
\text { sesuai untuk mencapai tujuan pembelajaran }\end{array}$ & $3,90(0,80)$ & $2,78(0,65)$ & 10,45 \\
\hline 38 & $\begin{array}{l}\text { Mempersiapkan materi dan metode } \\
\text { pembelajaran }\end{array}$ & $3,57(0,85)$ & $2,56(0,96)$ & 8,94 \\
\hline 39 & $\begin{array}{l}\text { Membuat praktik klinik menjadi pengalaman } \\
\text { yang menyenangkan }\end{array}$ & $3,90(0,91)$ & $2,48(0,98)$ & 11,93 \\
\hline 40 & Objektif dalam mengevaluasi mahasiswa & $4(0,79)$ & $2,72(0,92)$ & 10,86 \\
\hline
\end{tabular}

\section{PEMBAHASAN}

Tabel 1 menunjukkan bahwa menurut persepsi mahasiswa, pembimbing klinik yang efektif yaitu yang utamanya mempunyai kompetensi profesional (mean 4,01). Hasil analisis kuesioner, mean tertinggi di pernyataan pembimbing klinik selalu mempunyai hubungan yang baik dengan tenaga kesehatan lain dan mempunyai pengetahuan yang cukup banyak. Sementara, untuk mean terrendah di pernyataan pembimbing klinik menghindari perilaku otoriter dan mendominasi mahasiswa. Persepsi mahasiswa tentang pembimbing klinik yang tidak efektif, karakter pribadi (mean 2,63) merupakan aspek yang paling tidak disukai. Hasil analisis kuesioner, mean terendah di pernyataan pembimbing klinik tidak pernah menerangkan dan mencontohkan teknik tindakan yang terbaru. Berdasarkan uji $t$ test, terdapat perbedaan antara pembimbing klinik efektif dan tidak efektif, perbedaan terbesar di kemampuan mengajar, kemudian di kompetensi profesional. Berdasarkan analisis $t$ test 40 pernyataan, ada satu yang tidak menunjukkan ada perbedaan ( $p$ value 0,757 ) yaitu di pernyataan pembimbing klinik menghindari supervisi yang berlebihan ke tugas-tugas mahasiswa.

Berdasarkan hasil penelitian, komponen kompetensi profesional menjadi hal yang utama agar pembimbing klinik berperan efektif. Kompetensi profesional adalah kemampuan yang harus dimiliki dalam perencanaan dan pelaksanaan proses pembelajaran mengarahkan kegiatan belajar mahasiswa untuk mencapai tujuan pembelajaran. Kompetensi profesional yang harus dimiliki seorang pembimbing klinik diantaranya tertarik dalam perawatan pasien, berlaku teori dalam praktik klinik, panutan bagi 
mahasiswa, terampil dalam teknik keperawatan, memiliki pengetahuan profesional, menjelaskan dan menunjukkan teknik-teknik baru. Hasil penelitian ini sejalan dengan hasil penelitian Bifftu et all (2018), menurut persepsi mahasiswa, pembimbing klinik yang efektif yaitu yang pertama harus mempunyai kemampuan mengajar, yang kedua kompeten yang ketiga mempunyai karakter pribadi yang baik.

Hasil penelitian ini berbeda dengan penelitian sebelumnya. Berdasarkan hasil penelitian sebelumnya terkait persepsi mahasiswa tentang pembimbing klinik yang efektif dan tidak efektif yaitu berbeda dalam kategori hubungan interpersonal dan karakteristik pribadi. Kategori kompeten secara professional dan kemampuan mengajar menurut persepsi mahasiswa tentang pembimbing klinik yang efektif dan tidak efektif perbedaannya kecil. Hasil pembelajaran yang baik akan tercapai apabila mahasiswa telah memperoleh arahan, umpan balik yang tepat terhadap kegiatan, sikap dan penampilan dan laporan yang telah disampaikan mahasiswa selama proses pembelajaran. Hubungan yang harmonis antara pembimbing dan mahasiswa selama proses pembelajaran menjadi bermakna terhadap keberhasilan mahasiswa dalam praktik klinik (Fu-in Tang et all, 2009).

Pengetahuan dan kompetensi klinik disini meliputi pengetahuan akan ilmu keperawatan yang dimiliki pengajar harus luas dan memahaminya secara mendalam. Disamping ilmu keperawatan yang diberikan kepada peserta didik, pengajar juga harus memiliki pengetahuan akan materi-materi yang berhubungan dengan hal itu. Kemampuan untuk menganalisa teori dan mengumpulkannya dari berbagai sumber, menitikberatkan pada pemahaman, kemauan untuk mendiskusikan dengan peserta didik mengenai pandangan atau pendapat yang berkaitan dengan bimbingan. Pengajar klinik yang efektif juga berperan sebagai perawat pelaksana (clinician). Mempertahankan kompetensi klinik sangat penting, diantaranya untuk dapat mengembangkan pengetahuan dan keterampilan peserta didik (Baker, 2012).

Terkait pembimbing klinik yang tidak efektif, menurut persepsi mahasiswa adalah di komponen karakteristik pribadi pembimbing klinik. Tampak bahwa ketika mahasiswa tidak menyukai pembimbing klinik, itu dikarenakan sikap (karakter pribadi) dari pembimbing klinik tersebut. Mengapa karakter pribadi pembimbing klinik menjadi sangat penting. Ketika mahasiswa sedang praktik di klinik, biasanya akan mengalami stres. Pertama, mungkin karena takut melakukan kesalahan, kedua takut pasien dan keluarga akan menolak dilakukan tindakan oleh mereka (Suikkala \& Leino, 2010). Dalam keadaan ini, karakter pribadi pembimbing klinik yang ramah dan suportif sangat penting bagi mahasiswa. Dalam penelitian ini, menurut mahasiswa, pembimbing klinik yang tidak efektif dikarenakan pembimbing klinik tidak pernah menerangkan dan mencontohkan teknik tindakan yang terbaru. Menurut asumsi peneliti, hal ini bisa dikarenakan peran ganda pembimbing klinik, sebagai pembimbing klinik juga sebagai kepala ruang atau ka tim atau bisa juga karena beban kerja perawat yang tinggi.

Menurut Madhavan prabhakaran (2013), pembimbing klinik yang efektif yaitu pembimbing yang mengevaluasi mahasiswa secara objektif, menjadi role model, mempunyai kompetensi klinik dan keterampilan komunikasi serta menghargai kemampuan mahasiswa. Hal ini sejalan dengan hasil penelitian ini yang menunjukkan bahwa pembimbing klinik yang efektif yaitu pembimbing yang mendemonstrasikan kemampuan teknik dan prosedur klinis, menunjukan keterampilan komunikasi, memberikan saran-saran spesifik untuk perbaikan, menunjukkan rasa empati, mengakui kekurangan dan kelebihan yang dimiliki, dan berpikiran terbuka serta tidak menghakimi.

\section{KESIMPULAN DAN SARAN}

Hasil penelitian menunjukkan bahwa menurut persepsi mahasiswa, pembimbing klinik yang efektif jika mempunyai kemampuan mengajar dan mempunyai kompetensi profesional, sehingga harapannya pembimbing klinik akan meningkatkan kemampuan mengajar dan kompetensi profesional untuk membantu mahasiswa mencapai tujuan pembelajaran klinik.

Bagi pembimbing klinik, untuk meningkatkan kompetensi professional dan 
kemampuan mengajar agar dapat memberikan bimbingan yang efektif ke mahasiswa serta untuk peneliti selanjutnya penelitian tentang faktor-faktor yang mempengaruhi kinerja pembimbing klinik (misalnya beban kerja).

\section{DAFTAR PUSTAKA}

Baker. (2012). Senior Nursing Students' Perception of Clinical Teacher Behavior. Nursing Theses and Capstone Projects. https://digitalcommons.gardnerwebb.edu/nursing_etd

Bergman, K., \&Gaitskill, T. (2010). Faculty and student perceptions of effective clinical teachers: An extension study. Journal of Professional Nursing, 6(1), 33-44.

Bifftu, Dachew, Tiruneh, Ashenafie, Tegegne, Worku. (2018). Effective Clinical Teaching Behaviors Views of Nursing Students and Nurse Educators at University of Gondar, Northwest Ethiopia: Cross-Sectional Institution Based Study. Journal of Caring Science 2018 Sep; 7(3): 119-123.Published online $2018 \quad$ Sep 1. doi: $10.15171 /$ jcs.2018.019

Clayton, B.L., Lypek, D.J., \& Connelly, L.M. (2010). Faculty perceptions of characteristics needed for clinical success at military nurse anesthesia programs AANA Journal, 68, 515-523.

DeLong, T.H., \& Bechtel, G.A. (2009). Enhancing relationships between nursing Faculty and clinical preceptors. Journal for Nurses in Staff Development, 15, 148-151.

Dunn, S.V., \& Hansford, B. (2010). Undergraduate nursing students' perceptions of their clinical learning environment. Journal of Advanced Nursing, 25, 1299-1306.

Fu-in Tang P, RN; Shieu-ming Chou, DSN, Hsienhsien Chiang, MSN, RN. (2009). Student Perception of Effective and Ineffective Clinical Instructors. 2009;44(4)

Gillespie. (2010). Student Teacher Connection in Clinical Nursing Education. J. Adv. Nurs. 37, 566-576.
Heshmati-Nabavi F, Vanaki Z. Professional approach: the key feature of effective clinical educator in Iran. Nurse Educ Today. 2010;30(2):163-8. doi: 10.1016/j.nedt.

Johnsen, K.O., Aasgaard, H.S., Wahl, A.K., \&Salminen, L. (2009). Nurse educator competence: A study of Norwegian nurse educators' opinions of the importance and application of different nurse educator competence domains. Journal of Nursing Education, 41, 295-301.

Killam \&Heerschap. (2012). Challenges to Student Learning in the Clinical Setting: A Qualitative Descriptive Study, 33 (6), 684691.

Lawal, Weaver, Bryan, Lindo. (2016). Factors that Influence the Clinical Learning Experience of Nursing Student at A Caribbean School of Nursing. Journal of Nursing Education and Practice, 6 (4).

Madhavanprabhakaran (2013),Undergraduate Nursing Student' Perception of Effective Clinical Instructor: Oman. International Journal of Nursing Science 2013, 3(2): 3844

Papp, I., Markkanen, M., \& von Bonsdorff, M. (2009). Clinical environment as a learning environment: Student nurses' perceptions concerning clinical learning experiences. Nurse Education Today, 23, 262-268.

Resnayati Y. (2012). Faktor Determinan Pengalaman Belajar Klinik Keperawatan Medikal Bedah pada Mahasiswa DIII Keperawatan.

Suikkala, A., \&Leino-Kilpi, H. (2010). Nursing student-patient relationship. Journal of Advanced Nursing, 33, 42-50.

Swarjana. (2014). Metodologi Penelitian Kesehatan. Yogyakarta: ANDI

Toelke LD. (2012). The clinical nurse instructor: best practices in orienting newly ill red clinical faculty. 